\title{
Economics
}

2019; 8(4): 149-155

http://www.sciencepublishinggroup.com/j/eco

doi: $10.11648 /$ j.eco.20190804.14

ISSN: 2376-659X (Print); ISSN: 2376-6603 (Online)

\section{Two-way Interactive Effect Between Financial Pressure \& Public Service Charges}

\author{
Yang Le \\ School of Public Finance and Tax, Central University of Finance and Economics, Beijing, China \\ Email address: \\ 1285112286@qq.com \\ To cite this article: \\ Yang Le. Two-way Interactive Effect Between Financial Pressure \& Public Service Charges. Economics. Vol. 8, No. 4, 2019 , pp. 149-155. \\ doi: $10.11648 /$ j.eco. 20190804.14
}

Received: October 28, 2019; Accepted: November 18, 2019; Published: November 21, 2019

\begin{abstract}
After the reform of the tax system, with the upward movement of financial power and the decentralization of power, the financial pressure of local governments in China has become increasingly prominent. As the previous model concluded, fiscal pressure may be the driving force behind the increase in local government public service charges. Therefore, it is necessary to study the interaction between financial pressure and public service charges. In this paper, it mainly researches two-way interactive effect between financial pressure and public service charges. The data of 31 provinces in China from 1999 to 2017 was used to construct the simultaneous equations model for fiscal pressure and public service charges, and then the empirical test was carried out for the interactive effect between the two with 3sls method. The research results show shown that there is an interactive effect between fiscal pressure and public service charges. That is, the public service charges is increased with the increase of fiscal pressures, explaining that when the government is facing financial pressure, the government will look for public service charges to make up for the gap in fiscal revenue and expenditure. The fiscal pressure is decreased with the increase of public service charges, explaining that public service charges are an effective way to ease financial pressure. In addition, the effect degree of the control variables related to financial autonomy and public service charges was analyzed in this paper.
\end{abstract}

Keywords: Fiscal Pressure, Public Service Charges, Two-way Interactive Effect

\section{Introduction}

As everyone knows that public service charges play an important role in China. However, the charging status is different in different levels of government, which is getting higher and higher from the central to the local [1]. Due to the poor charging system and supervision, many grassroots governments have problems of irregular and illegal charges, which greatly increase the burden on enterprises. In response to this problem, Chinese governments at all levels have vigorously promoted the reform of decreasing charges since 2015, with an amazing amount of decreasing charges. By the end of 2018, the central government decreased the number of pricing and charging items by more than half, leaving only five items. In contrast, the local governments decreased the number of pricing and charging items by nearly half, leaving only 13 items in average. Among them, there is the largest number of administrative and institutional charging items related to enterprises, which is also the main part of decreasing charges. A total of 35 charging items were canceled. Besides,
NPC (National People's Congress of the people's Republic of China) and CPPCC (Chinese People's Political Consultative Conference) determined the "decrease of taxes and charges" as the key task in 2018.

In 1994, the reform of tax-sharing system was implemented in China. Finally, it achieved great success, successfully mobilized the enthusiasm of local governments and promoted the development of local economy. But there were still a series of problems of tax-sharing system [2]. At present, the tax-sharing system between the governments below the provincial level in China has not been perfected. The long-standing "hidden rules" of officialdom politics have made it impossible for the lower-level governments to have an advantage over the higher-level governments for the issues, such as proportion of financial resources and tax categories, etc., but they could only passively accept the financial resources allocation of the higher-level government. As a result, the financial resources have been moved upward continuously and the power of governments has been decentralized continuously, thus making the grassroots governments live more and more 
difficultly [3]. Meanwhile, the policy centering on economic construction was vigorously implemented in China, and decentralization and profit-sharing were implemented for enterprises, so that the situation of unified administration in the planned economy period was broken, but the situation of unified distribution was not broken [4]. One the one hand, the local governments must ensure the development of local economy and keep the fiscal expenditures as former. On the other hand, they must reduce the burden on enterprises, thus making the tax revenues reduce, resulting in a situation that the revenue could not cover the expenditure and local governments must face the increasing financial pressure [5].

Is there an interactive relationship between public service charges and financial pressure in the realistic background of the continuous deepening of tax and charges reduction reform and the huge financial pressure? What is the influence path between them? The answers to these questions are of important theoretical and practical significance for us to implement the reform of tax and charges reduction and alleviate financial pressure.

One-way correlation between financial pressure and public service charges is mainly analyzed in the current literature. Firstly, it analyzes the influence of financial on public service charges, showing that the financial pressure has a significant positive effect on public service charges [6]. Secondly, it analyzes the influence of public service charges on financial pressure, showing that the increase of public service charges can reduce the financial pressure [7]. Furthermore, there are two main problems in the current research literature. First of all, most literature have studied one-way correlation between financial pressure and public service charges, but few research on two-way interactive effect [8]. Second, the correlation between the influence factors of financial pressure and public service charges is not considered and there is a multiple collinearity problem in the regression process, thus affecting the rationality of the research results. In this paper, it researched the current literature and sorted out the interactive effect between the two, as well as established a theoretical framework and considered the relevant factors that affect the financial pressure and public service charges. Moreover, the panel data of provinces from 1999 to 2017 was used to establish simultaneous equations for financial pressure and public service charges, and three-stage least squares method was used to carry out an empirical test for their two-way interactive effect.

\section{Literature Review}

\subsection{Research on the Influencing Mechanism of Financial Pressure on Public Service Charges}

There are two paths of influencing mechanism of financial pressure on public service charges. The first one is the implementation of tax-sharing system, resulting in the mismatch between the central and local powers and financial powers. As a result, the government has to face a huge financial revenue and expenditure gap and increase the public service charges. The second is the implementation of policy centering on economic construction. The local economy is vigorously developed and the expenditure is increased continuously, resulting in a situation that the revenue could not cover the expenditure and the expenditure is made up by increasing charges.

In 1994, the tax-sharing system was implemented in China, leading to a mismatch between financial power and the power of governments. After the implementation of tax-sharing system, the financial resources continued to move upwards and the power of governments continued to decentralize. As a result, the public has increasing requirements for the quantity and quality of public goods, the scope and connotation of the government's powers continued to expand, and the expenditures continued to increased. The relatively fixed tax sources and steady tax revenue growth rate had a weaker support for the rapid growth of financial expenditure scale [9]. Therefore, the government had to continuously increase the public service charges in the face of increasing gap between revenue and expenditure.

At present, China is still in the primary stage of socialism. On the one hand, it is the top priority of all levels of government to develop the economy, which is also the main basis for the evaluation and selection system of cadres. On the other hand, the local governments strongly hope to develop the local economy to win the appreciation of higher-level governments and gain more political promotion opportunities. Currently, the rapid development of China's economy is still in an investment-driven stage. Therefore, the function orientation centering on economic development has made the local governments focus on project investment and take the increase of infrastructure construction as their primary goal, thus causing the increasingly expanding fiscal expenditure. The governments have to seek charges to make up the infrastructure construction funds.

\subsection{Research on the Influencing Mechanism of Public Service Charges on Financial Pressure}

There are two paths of influencing mechanism of public service charges on financial pressure. The first one is to increase the public service charges, which can provide financial guarantee for the normal operation of all departments, thereby narrowing the gap between fiscal revenue and expenditure. The second one is that the increase in public service charges can provide sufficient funds for infrastructure construction, thereby alleviating the financial pressure caused by economic construction.

As we all know that the public service charges are the main source of revenue for the normal operation of enterprises and institutions. Welch proposed a public finance paradox. That is, people want to pay as little taxes as possible, but get as many public services as possible [10]. Now, the scale of public services has been expanded with the continuous deepening of the reform of the fiscal and tax system and the continuous development of the economy [11]. In the case of limited space for tax revenue growth [12], the government can only seek new sources of revenue to provide sufficient public services. Simultaneously, public service charge is an important means 
of government administration according to law. Instead of purely relying on the administrative enforcement of law, it is necessary for the government to rely on economic means to become a good "person in charge" of economic operation. Actually, it is an important way to realize the economic means to establish the enterprises and institutions that can provide various public services. However, there are too many enterprises and institutions, so tax can not guarantee the revenue, while the public service charges can allow them to realize "self-revenue and self-expenditure", thus ensuring their healthy operation.

Public service charge follows the principle of beneficiary payment, while the special revenue meets the special expenditure. The governments need to build public service infrastructures to improve the public service level. A large number of funds are required to invest in the construction of large public service infrastructures, but many infrastructures can provide the universal public services. As a result, the governments can not get sufficient tax revenue, but it does not meet the principle of beneficiary burden to provide by tax revenue, so the public services are charged. In China, many items of public service charges are introduced to compensate for the funding gap in infrastructure construction now.

\section{Empirical Research}

\subsection{Theoretical Framework}



Figure 1. Theoretical framework of two-way interactive effect between financial pressure and public service charges.

According to Figure 1, we analyze the interactive effect between financial pressure and public service charges from two directions. The first one is the influence of financial pressure on public service charges. The public service charges increase with the increase of financial pressure. The reform of tax-sharing system and the policy orientation centered on economic construction have caused the government expenditures increased, resulting in a situation that the revenue could not cover the expenditure and the expenditure is made up by increasing public service charges. The second one is the increase in public service charges, which can effectively reduce financial pressure. Such increase can provide sufficient funds for the operation of all departments and the funds needed for infrastructure construction, resulting in an increase in government revenue to alleviate the situation that the revenue could not cover the expenditure.

\subsection{Measurement Model and Data}

In this paper, the simultaneous equations were constructed to empirically investigate the two-way feedback effect between financial pressure and public service charges. Simultaneous equations can not only effectively solve the endogeneity problem of explanatory variables, but also comprehensively analyze the influence of other control variables on financial pressure and public service charges based on the empirical analysis results.

\subsubsection{Measurement Model}

$$
\begin{aligned}
& \operatorname{lncharges} \text { it }_{i t}=\beta_{0}+\beta_{1} \text { ade }_{i t}+\beta_{2} \text { gscal }_{i t}+\beta_{3} \ln \text { wage }_{i t}+\beta_{4} \ln \text { garea }_{i t}+D_{q y}+e_{i t} \\
& \text { ade }_{i t}=\gamma_{0}+\gamma_{1} \ln \text { ch } \operatorname{arges}_{i t}+\gamma_{2} \text { open }_{i t}+\gamma_{3} \text { indus }_{i t}+\gamma_{4} \text { urban }_{i t}+\gamma_{5} \ln p g d p_{i t}+D_{q y}+u_{i t}
\end{aligned}
$$

Wherein, equation (1) refers to the public service charge equation and equation (2) refers to the financial pressure equation. The letter "i" stands for each province and the letter
" $t$ " stands for each year. In the public service charge equation, gscal $_{i t}$ stands for the scale of the government of $\mathrm{i}$-th province 
in t-th year; $\ln$ wage $_{i t}$ stands for the natural logarithm of the average wage of employees in non-private enterprises in i-th province in $\mathrm{t}$-th year; $\ln$ garea $_{i t}$ stands for the natural logarithm of urban garden green area of i-th province in t-year and $e_{i t}$ is a random item. In the financial pressure equation, open $_{i t}$ stands for the degree of openness of $\mathrm{i}$-th province in $\mathrm{t}$-th year; indus $s_{i t}$ stands for the industrial structure of $i$-th province in t-th year; urban $_{i t}$ stands for the urbanization rate of i-th province in t-year; $\ln p g d p_{i t}$ stands for the natural logarithm of per capita gdp of $\mathrm{i}$-th province in $\mathrm{t}$-th year and $u_{i t}$ is a random term. $D_{q y}$ is a regional dummy variable, while the eastern region is $q \mathrm{y}=1$ and the central and western regions are $\mathrm{qy}=0$.
The time effects of individual variables is eliminated with a natural logarithmic mode.

\subsubsection{Data Source and Processing}

In this paper, the panel data is used for statistical analysis, with 31 provinces as the research objects. But Taiwan, Hong Kong Special Administrative Region and Macao Special Administrative Region are not included in this research due to the missing of partial data and inconsistent statistical caliber. The time span is from 1999 to 2017 and all the data in this paper are from China Statistical Yearbook, China Finance Yearbook and China Population and Employment Statistics Yearbook.

Table 1. Descriptive statistics.

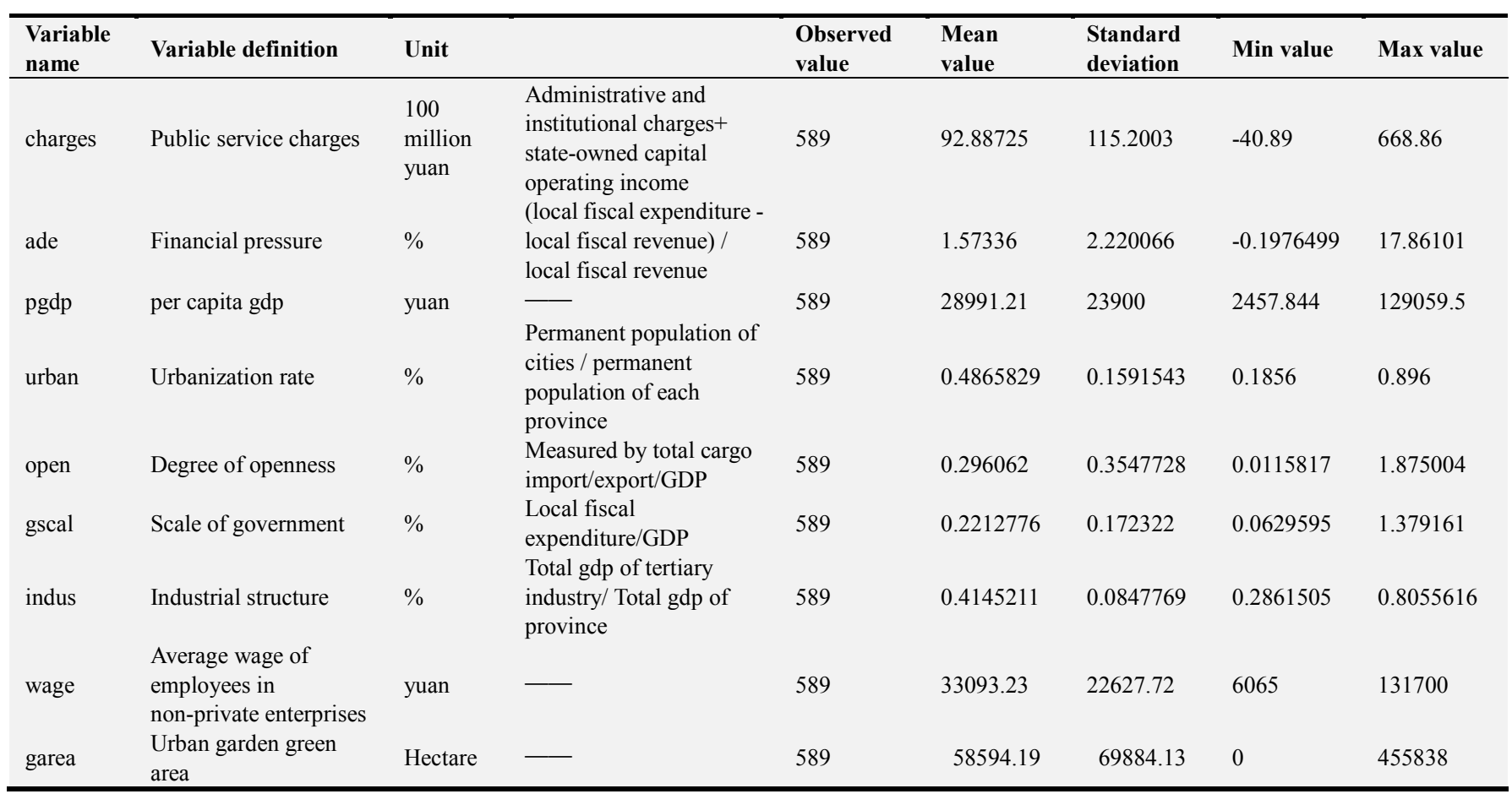

The public service charges variable and financial pressure variable are the main endogenous variables in this paper. The control variables of public service charge equation mainly include the scale of the government, the average wage of employees in urban non-private units and the urban garden green area. The control variables of financial pressure equation mainly include degree of openness, industrial structure, urbanization rate and per capita GDP.

\subsection{Analysis of Estimation Method and Empirical Result}

\subsubsection{Estimation Method}

In this paper, the complete information system estimation method was used to construct simultaneous equations. This method can not only effectively interpret the correlation between endogenous variables, but also include the influence of control variables on endogenous variables. [13] The complete information system estimation method mainly adopts the 3sls method, which is more effective than 2 sls adopted by finite information sheet estimation method and the maximum likelihood estimation adopted by limited information. Moreover, the order conditions and rank conditions that should be satisfied by the simultaneous equations were identified, including five variables not included in the public service charge equation and 4 variables not included in the financial decentralization equation. The simultaneous equations satisfy the order conditions and rank conditions. The estimation analysis is carried out as follows. 


\subsubsection{Analysis of Regression Results}

Table 2. Estimation results.

\begin{tabular}{|c|c|c|c|c|c|c|c|}
\hline \multicolumn{4}{|l|}{ Model 1} & \multicolumn{4}{|l|}{ Model 2} \\
\hline \multicolumn{2}{|c|}{ Public service charge equation } & \multicolumn{2}{|c|}{ Financial pressure equation } & \multicolumn{2}{|c|}{ Public service charge equation } & \multicolumn{2}{|c|}{ Financial pressure equation } \\
\hline $\begin{array}{l}\text { Explanatory } \\
\text { variable } \\
\end{array}$ & $\begin{array}{l}\text { Regression } \\
\text { coefficient }\end{array}$ & $\begin{array}{l}\text { Explanatory } \\
\text { variable } \\
\end{array}$ & $\begin{array}{l}\text { Regression } \\
\text { coefficient }\end{array}$ & $\begin{array}{l}\text { Explanatory } \\
\text { variable }\end{array}$ & $\begin{array}{l}\text { Regression } \\
\text { coefficient }\end{array}$ & $\begin{array}{l}\text { Explanatory } \\
\text { variable }\end{array}$ & $\begin{array}{l}\text { Regression } \\
\text { coefficient }\end{array}$ \\
\hline ade & $\begin{array}{l}0.621 * * * \\
{[0.1135]}\end{array}$ & lncharges & $\begin{array}{l}-1.617 * * * \\
{[0.0785]}\end{array}$ & ade & $\begin{array}{l}0.538 * * * \\
{[0.1030]}\end{array}$ & lncharges & $\begin{array}{l}-1.600 * * * \\
{[0.0749]}\end{array}$ \\
\hline gscal & $\begin{array}{l}-8.234 * * * \\
{[1.1014]}\end{array}$ & open & $\begin{array}{l}0.697 * * \\
{[0.2442]}\end{array}$ & gscal & $\begin{array}{l}-8.048 * * * \\
{[0.9900]}\end{array}$ & open & $\begin{array}{l}1.646 * * * \\
{[0.2713]}\end{array}$ \\
\hline lnwage & $\begin{array}{l}1.243 * * * \\
{[0.0807]}\end{array}$ & indus & $\begin{array}{l}2.196 \\
{[1.1291]}\end{array}$ & lnwage & $\begin{array}{l}1.311 * * * \\
{[0.0732]}\end{array}$ & indus & $\begin{array}{l}2.715^{*} \\
{[1.0787]}\end{array}$ \\
\hline lngarea & $\begin{array}{l}0.942 * * * \\
{[0.0751]}\end{array}$ & urban & $\begin{array}{l}-15.60 * * * \\
{[0.8413]}\end{array}$ & lngarea & $\begin{array}{l}0.918 * * * \\
{[0.0678]}\end{array}$ & urban & $\begin{array}{l}-14.87 * * * \\
{[0.8130]}\end{array}$ \\
\hline _cons & $\begin{array}{l}-17.87 * * * \\
{[1.0554]}\end{array}$ & lnpgdp & $\begin{array}{l}3.394 * * * \\
{[0.1738]}\end{array}$ & _cons & $\begin{array}{l}-18.02 * * * \\
{[0.9491]}\end{array}$ & lnpgdp & $\begin{array}{l}3.379 * * * \\
{[0.1664]}\end{array}$ \\
\hline & & cons & $\begin{array}{l}-19.62 * * * \\
{[1.1647]}\end{array}$ & & & _cons & $\begin{array}{l}-19.93 * * * \\
{[1.1203]}\end{array}$ \\
\hline- & - & - & - & qy & $\begin{array}{l}-0.581 * * * \\
{[0.0825]}\end{array}$ & qy & $\begin{array}{l}-1.289 * * * \\
{[0.1811]}\end{array}$ \\
\hline $\mathrm{N}$ & 574 & $\mathrm{~N}$ & 574 & $\mathrm{~N}$ & 574 & $\mathrm{~N}$ & 574 \\
\hline AIC & 3647.2 & & & AIC & 3486.8 & & \\
\hline $\mathrm{BIC}$ & 3695 & & & $\mathrm{BIC}$ & 3543.3 & & \\
\hline
\end{tabular}

Table 2 shows the estimation results of public service charges and financial pressure. Among them, model 1 is the result not included the regional dummy variable and model 2 is the regression result included the regional dummy variable. According to the results, on the one hand, the public service charge equation and the financial pressure equation have significant regional effects after introducing the regional dummy variables, while the regression coefficients of the regional dummy variables pass the significance test. On the other hand, the significance of regional dummy variable to other variables does not change, and the regression coefficient of each variable does not change much. Therefore, the region only has an effect on public service charges and financial pressure, but no effect on control variables. Through screening, Model 2 is selected to analyze the two-way interactive effect between financial pressure and public service charges.

i. The influence of financial pressure on public service charges. According to the regression results of Model 2, the regression coefficient of financial pressure on public service charges is 0.538 , passing the significance test of $1 \%$. This means that the government's demand for public service charges increases by $0.538 \%$ when the gap between fiscal revenue and expenditure increases by $1 \%$, which is consistent with the analysis above. That is, the governments seek to increase the public service charges to make up for the large gap between revenue and expenditure after the implementation of tax-sharing system [14].

ii. The influence of public service charges on financial pressure. According to the regression results of Model 2, the regression coefficient of public service charges on financial pressure is -1.6 , passing the significance test of $1 \%$. This means that the gap between fiscal revenue and expenditure decreases by $1.6 \%$ when the public service charge increases by $1 \%$, which is consistent with the analysis above. That is, the public service charges can effectively solve the large gap between fiscal revenue and expenditure.

iii. The influence of public service charge control variables on public service charges. The regression result of the scale of government on public service charges is -8.048 , passing the significance test of $1 \%$. This means that the public service charges decrease by $-8.048 \%$ when the scale of government increases by $1 \%$, indicating that the executive powers of the government are expanded with the expansion of its scale. As power expands, the government can gain more monopoly advantages to less rely on the public service charges within the budget. The regression result of average wage of employees in urban non-private enterprises on public service charges is 1.311 , passing the significance test of $1 \%$. This means that the public service charges increase by $1.311 \%$ when the average wage of employees in urban non-private enterprises increases by $1 \%$. The operation of state-owned enterprises and collective enterprises is largely burdened by public service charges, so the public service charges will be increased with the increase of the wages of employees in the state-owned enterprises. The regression result of urban garden green area on public service charges is 0.918 , passing the significance test of $1 \%$. This means that the public service charges increase by $0.918 \%$ when the urban garden green area increases by $1 \%$, indicating that a large part of the expenditure gap of expanding the urban garden green area should be made up by government public service charges.

iv. The influence of financial pressure control variables on financial pressure. The regression result of openness degree on financial pressure is 1.646, passing the significance test of $1 \%$. This means that the financial pressure increases by $1.646 \%$ when the degree of 
openness increases by $1 \%$. The economy can develop with the increase of openness degree, so the government regulates the economy, thus increasing more expenditure and financial pressure. The regression result of industrial structure on financial decentralization is 2.715 , passing the significance test of $1 \%$. This means that the financial pressure increases by $2.715 \%$ when the industrial structure increases by $1 \%$, indicating that the government's financial pressure increases with the increase in the proportion of tertiary industry. The regression result of the degree of urbanization on financial decentralization is -14.87 , passing the significance test of $1 \%$. This means that the financial pressure decreases by $14.87 \%$ when the degree of urbanization increases by $1 \%$, indicating that the financial pressure can be effectively alleviated by increasing the degree of urbanization. The regression result of per capita GDP on financial pressure is 3.379, passing the significance test of $1 \%$. This means that the financial pressure increases by $3.379 \%$ when per capita GDP increases by $1 \%$, indicating that the public demands for public service with the improvement of people's living standards, thus increasing more the government's expenditure and financial pressure.

\section{Conclusion and Suggestions}

\subsection{Conclusion}

In this paper, the empirical test was carried out for the interactive effect between financial pressure and public service charges through simultaneous equations. The research results show that there is a positive correlation between financial pressure and public service charges when financial pressure affects public service charges. In contrast, there is a negative correlation between public service charges and financial pressure when public service charges affect financial pressure. According to the influence analysis on control variables, there is a negative correlation between the scale of government and public service charges. There is a positive correlation between the average wage of employees in urban non-private units, urban garden green area and public service charges. There is a negative correlation between urbanization and financial pressure. There is a positive correlation between the degree of openness, industrial structure, per capita GDP and financial pressure.

\subsection{Suggestions}

It is necessary to fully consider the two-way interactive effect of public service charges and financial pressure when promoting the reform of tax and charges reduction and alleviating financial pressure:

It should pay attention to the local financial pressure when implementing the reform of tax and charges reduction, because different regions have different economic development situation. Therefore, the tax and charges should be reduced flexibly as the circumstances may require, otherwise the local governments will collect more hidden and disguised charges. The power should be appropriately decentralized to allow the local governments to carry out targeted charges reduction according to the actual conditions of their respective jurisdictions, so as to avoid the severe fluctuations in fiscal revenue and local economy due to the charges reduction. Pay attention to giving full play to the initiative of local governments to "tax cut and fee reduction", and give better performance evaluations to local governments that have a good effect on tax reduction and fee reduction.

It is an effective means to increase public service charges when the government solves the problem of financial pressure. But instead of blindly increasing the charges, they should be included in the general budget to make the charges transparent In addition, it is required to follow the legal procedures and refer to the public opinions to standardize the charges when deciding whether to increase charges. Establish a performance evaluation indicator system [15] for public service charges so that charges are carried out under effective, equal and sufficient standards. By scoring different charging items, the current unreasonable charging phenomenon is solved, making the charges more reasonable and sufficient.

\section{References}

[1] Jia Bo. Transfer of Non-tax Revenue \& State Governance [J]. Tax Research, 2019 (06): 110-114.

[2] Hu Shudong. The Relationship between the Central and Local Governments in Economic Development--Research on Changes of China's Fiscal System [M], Shanghai: Shanghai People's Publishing House, 2001: 168.

[3] Sun Wenji. Analysis of the Status Quo and Reasons of Charges in China [J]. Journal of Suzhou University, 1999 (02): 33-36.

[4] Lv Wei \& Gao Shuaixiong. House Price Fluctuation, Land Finance and China's Macroeconomics [J]. Comparison of Economic and Social Systems, 2016 (4).

[5] Chen Shuo. The Influence, Causes and Countermeasures of Highway Tolls under the Central and Local Fiscal Patterns [J]. Statistical Research, 2014, 31 (09): 72-79.

[6] Li Yonghui \& Lin Sen. Research on Non-tax Revenue and Governance of Government [J]. Journal of Jishou University (Social Science Edition), 2018, 39 (01): 56-63.

[7] Welch \& Skedegard. Governance Rather Than Management [J]. Publishing Reference, 2003 (02): 30.

[8] Li Xuanjing. Analysis of the Influence of Administrative Charges on Government's Non-tax Revenue [J]. Market Research, 2018 (07): 72-73.

[9] Chen Kang, Arye L. Hillman and Gu Qingyang. Fiscal Centralization and Changes in Local Government Behavior: From Aid to Occupying [J]. Economics (Quarterly), 2002 (04): 111-130.

[10] Shu Hongtao. Contract Management of PPP Toll Road by Using the Cooperation between Government and Social Capital [J]. China Market, 2018 (26): 102-103. 
[11] Yang Yiyong, Wei Yifang and Gu Yan. The Normative Problem of Enterprise-related Charges Must be Attached Great Importance [J]. Price Theory and Practice, 2016 (04): 21-25.

[12] Li Yihua \& Han Fang. Research on Tax Competition, Financial Pressure and Non-tax Revenue between Local Governments [J]. Public Finance Research, 2018 (04): 56-72.

[13] Xu Xiuchuan. Empirical Research on Interaction between Urbanization, Industrialization and Urban-Rural Income Gap [J]. Agricultural Economic Issues, 2008 (12).
[14] Deng Xiaolan, Jin Bohan and Li Wei. Research on the Interaction of Local Fiscal Revenue and Expenditure in China--An Empirical Analysis Based on Provincial Panel VAR Model [J]. Financial Research, 2018 (07): 14-27.

[15] Lu Yangfan. Financial Revenue-Expenditure Performance Evaluation: Technical System and Implementation Path [J]. Financial Supervision, 2018 (12): 22-27. 